\title{
Protección fitosanitaria del arbolado urbano en San José, \\ Costa Rica
}

\author{
NOTA TÉCNICA
}

\section{Marcela Arguedas Gamboa ${ }^{1}$ \\ María Rodríguez Solís ${ }^{2}$}

1. Escuela de Ingeniería Forestal. Instituto Tecnológico de Costa Rica. Cartago, Costa Rica. marguedas@tec.ac.cr

2. Escuela de Ingeniería Forestal. Instituto Tecnológico de Costa Rica. Cartago, Costa Rica. mrodriguez@tec.ac.cr

\section{RESUMEN}

Los espacios verdes en las ciudades, incluyendo el arbolado cumplen múltiples funciones para beneficio de la sociedad. Generalmente, los árboles en la ciudad se encuentran en condiciones desfavorables para su salud, lo que disminuye su vigor y muchos de ellos se enferman. Para manejar cualquier problema fitosanitario, es indispensable realizar un diagnóstico que permita determinar claramente sus causas. Se describen en este artículo los principales problemas fitosanitarios detectados en la ciudad de San José (Costa Rica), producidos por agentes bióticos como insectos, ácaros, hongos, bacterias y muérdagos y otros factores limitantes para su desarrollo del arbolado.

Palabras clave: Arboricultura, Plagas, Enfermedades, San José, Costa Rica.

\section{ABSTRACT}

Plant protection of urban trees - the case of San José, Costa Rica. Green spaces in cities, including trees serve multiple functions for the benefit of society. Generally, trees in the city are under unfavorable conditions for their health, reducing its vigor and many of them are sick. To handle any phytosanitary problem, it is necessary to make a diagnosis that clearly identify their causes. This paper describes the main phytosanitary problems detected in the city of San José (Costa Rica), produced by biotic agents such as insects, mites, fungi, bacteria and mistletoes and other limiting factors for the development of trees.

Key Words: Arboriculture, Pests, Diseases, San José, Costa Rica. 
Los medios urbanos constituyen los núcleos más densamente poblados en nuestro planeta. Los espacios verdes, los árboles o cualquier otro tipo de vegetación cumplen múltiples funciones en estas áreas, son elementos esenciales para el mantenimiento de la calidad del medio y de la de vida de sus pobladores y se constituyen en un componente fundamental dentro de la planificación urbana (Jiménez 2013; Ordóñez \& Duinker, 2013; Tovar, 2013; Miller et al., 2015; Salbitano et al., 2016; Zúñiga-Sánchez 2017).

Las funciones de la arborización en sitios urbanos pueden ser sintetizados de la siguiente manera (Tovar 2006; ABM 2008, Escobedo et al., 2011; Fernández y Vargas, 2011; Sosa-Lopez et al., 2011; Livesley et al., 2016):

- Aporte estético, cultural y simbólico.

- Aporte al bienestar físico y sicológico, a la recreación, a la educación y al descanso.

- Atenuación o minimización de partículas, vientos, vectores, olores y ruido.

- Conformación de espacios y subespacios.

- Valoración de la propiedad privada y del espacio público.

- Protección de cuencas y cuerpos de agua y mejoramiento de suelos (control de erosión).

- Provisión de hábitats.

- Regulación climática y control de temperatura.

- $\quad$ Captación de dióxido de carbono (CO2).

- Aporte productivo, empleo e ingreso.

Los árboles urbanos son generalmente los grandes olvidados y los que se encuentran en condiciones desfavorables para su salud; la influencia de la contaminación atmosférica, las malas condiciones del sustrato de desarrollo y el vandalismo, disminuyen sustancialmente su vigor (Cibrián et al., 2007). El desarrollo de los árboles de ornamento se ve seriamente afectado por las limitaciones que presenta este tipo de medio en contraposición con las condiciones naturales de desarrollo en el bosque. Velar por el estado sanitario de estos árboles, constituye entonces, un aporte significativo para el mantenimiento de esta masa verde en las áreas densamente pobladas, tales como las ciudades (Arguedas 1993a; Boa, 2008; Villalobos, 2014; Laffont et al., 2015; Reyes de la Barra et al., 2018).

Para manejar correctamente cualquier anomalía detectada en un árbol, es indispensable realizar un diagnóstico que permita determinar claramente sus causas. Las principales afecciones que sufren los árboles de ornamento pueden agruparse en tres categorías: daños producidos por insectos, enfermedades infecciosas y enfermedades no infecciosas. Sin embargo, una anomalía presente en un árbol podría ser el resultado de la interacción de diversas afecciones agrupadas en las diferentes categorías mencionadas. Se describen a continuación problemas fitosanitarios de importancia en el arbolado urbano en la ciudad de San José, Costa Rica.

\section{DAÑOS PRODUCIDOS POR INSECTOS Y ÁCAROS}

Los insectos (Clase Insecta) y los ácaros (Clase Arachnida) herbívoros pueden producir una amplia gama de daños en plantas menores y árboles. Una de las características más importantes de reconocer en los insectos es el tipo de aparato bucal; dos tipos son particularmente importantes dentro de la entomología forestal: el aparato bucal tipo masticador y el succionador.

Los insectos masticadores presentan mandíbulas cortantes dispuestas a cada lado del aparato bucal, lo cual les permite cortar y masticar los alimentos. Los adultos de los órdenes Orthoptera (saltamontes), Coleoptera (abejones), Hymenoptera (hormigas), Isoptera (termitas) y todas las larvas en general, presentan este tipo de aparato bucal.

Otros insectos tienen adaptaciones de las mandíbulas y las maxilas en forma de un fino estilete, que les permite insertarlo en los tejidos y succionar la savia, como es el caso de especies del orden Hemíptera (chinches, áfidos, cigarritas, escamas, etc.). El orden Thysanoptera y los ácaros herbívoros representan individuos muy pequeños con un aparato bucal que raspa tejidos tiernos, lo que permite la salida de la savia y posteriormente su succión (Arguedas 2006a y b; Cibrián 2017). 


\section{Masticadores de follaje}

Es uno de los grupos más grandes y producen de los daños más comunes en la arboricultura. Estos grupos pueden producir defoliaciones totales y repetitivas, lo que puede llevar a la muerte a individuos jóvenes.

La "hormiga cortadora" (Atta spp.), defoliadora generalista, es común en espacios abiertos como parques o bosquetes. Los obreros de las colonias cortan hojas en trozos más o menos circulares, que transportan hasta sus nidos, donde los trituran y usan como sustrato para cultivar un hongo (Rozites gongylophora Moeller), el cual constituye su alimento principal. Las defoliaciones son generalmente muy severas y pueden causar la muerte de árboles recién establecidos. Los nidos son subterráneos y presentan túneles extensos, provistos con respiraderos; externamente aparecen montículos de tierra en los puntos de ingreso al nido (Fig. 1) (CATIE, 1991; Arguedas, 2004; Varón et al., 2007; Montoya-Lermas, 2012; Cibrián, 2013).
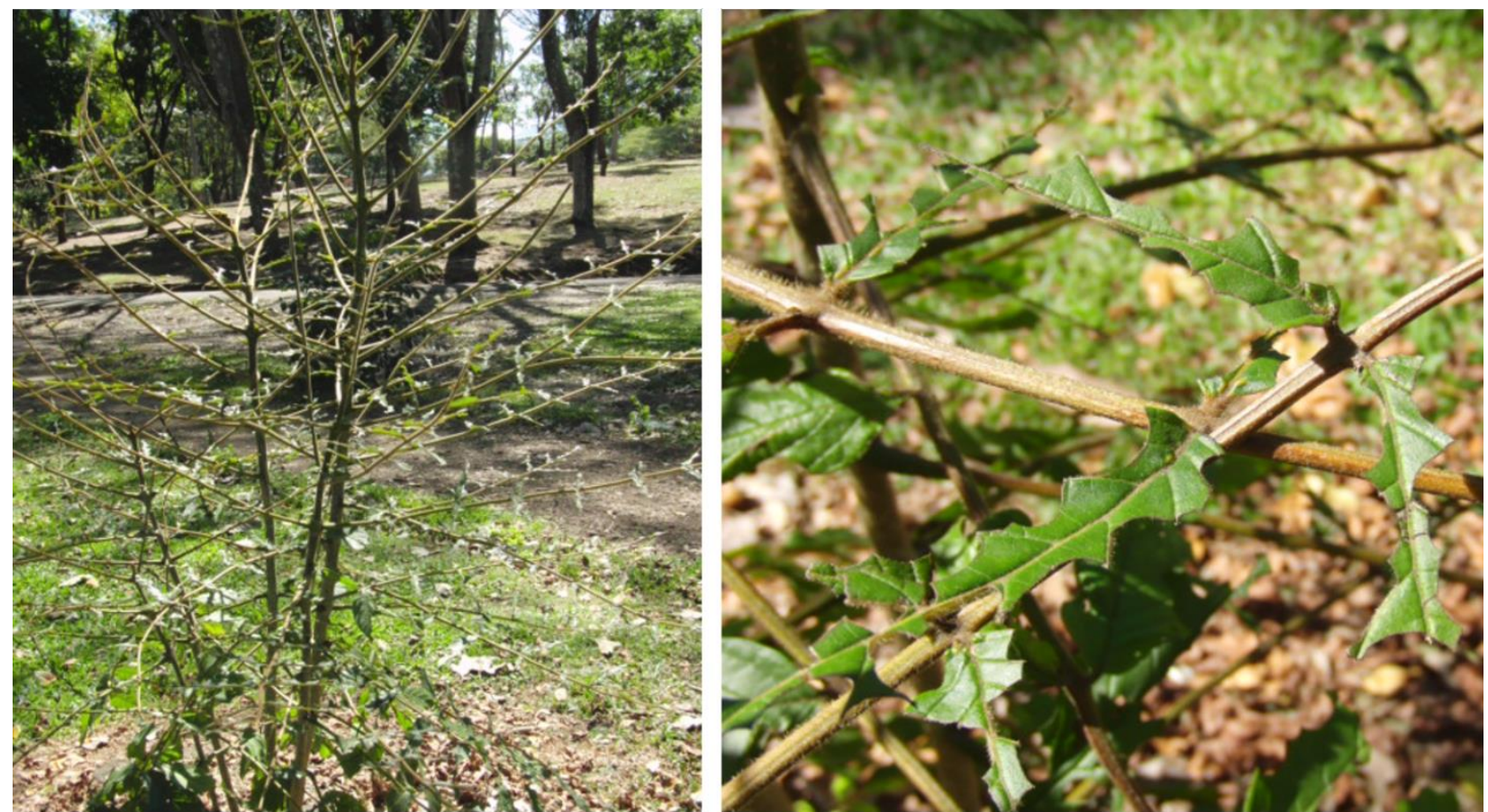

Figura 1. Defoliación total por Atta sp.(Formycidae, Hymenoptera). San José, Costa Rica.

Otras defoliaciones muy comunes en árboles ornamentales son las pequeñas y múltiples perforaciones que producen especies de la familia Chrysomelidae (Coloptera) (Fig. 2.A) o áreas devoradas mucho más extensivas producidas por saltamontes y larvas, especialmente el orden Lepidoptera, como las defoliaciones periódicas de Himeromima aulis (Geometridae) en Trichilia havanensis (Fig. 2.B) (Pitkin, 2002; Arguedas, 2007) o el generalista "gusano casita" (Oiketicus kirbii) (Mexzón et al., 2003; Rhainds y Cabrera-La Rosa, 2010). 

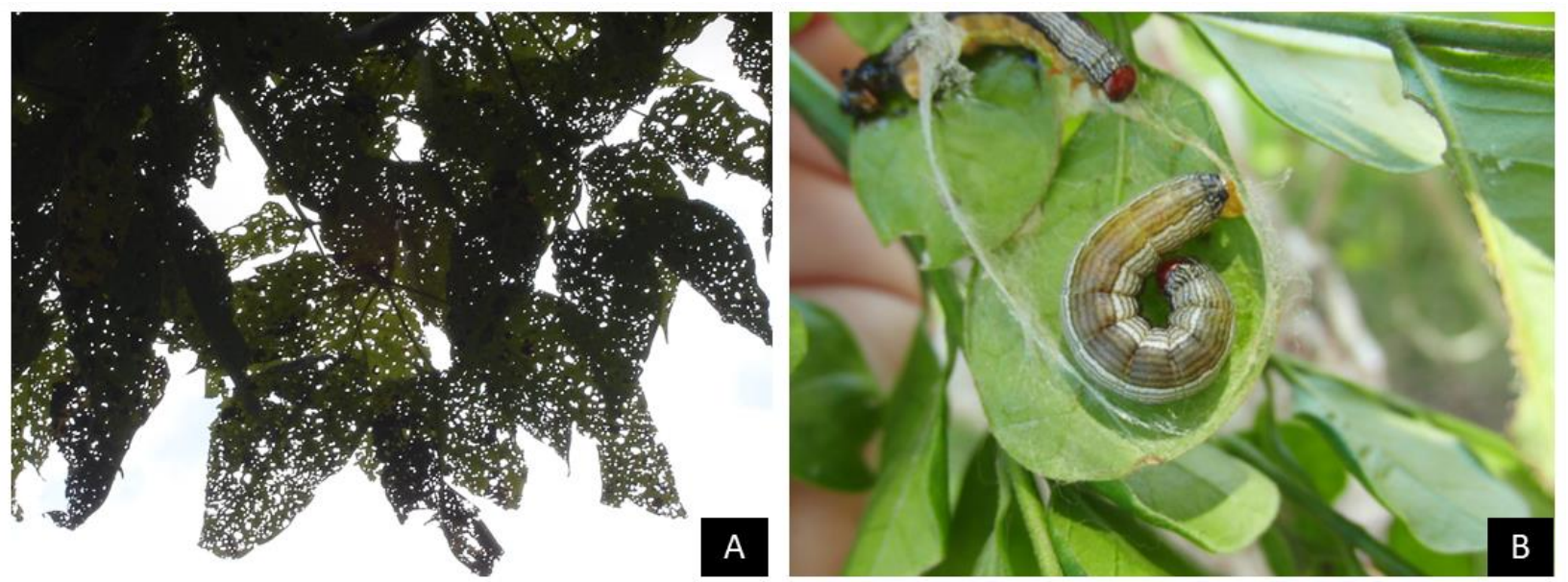

Figura. 2. Daños por insectos masticadores. A, Perforaciones múltiples por Rabdopterus sp. (Chrysomelidae, Coleoptera) en Tabebuia rosea; B, Larva y prepupa de Himeromima aulis (Geometridae, Lepidoptera) en Trichilia havanensis. San José, Costa Rica.

\section{Succionadores de follaje}

Estos insectos son generalmente de pequeñas dimensiones y viven en forma congregada, por lo que es posible encontrar individuos de todos los estados de su ciclo de vida. Muchas especies de succionadores son muy pequeños, pero no deben desestimarse los efectos de sus daños, ya que generalmente se encuentran en grandes cantidades y algunos son portadores de virus y otras enfermedades fitopatógenas.

Los "áfidos" o "pulgones" (Aphididae, Hemiptera) son insectos de cerca de un milímetro de longitud, poseen el cuerpo suave en forma de pera, antenas largas y al final del abdomen un par de conículos o "tubitos" por donde salen sustancias defensivas; además, secretan por el ano una sustancia dulce que atrae hormigas que aparentemente los protegen (Fig. 3.A). Los géneros más representativos son Aphis y Cinara (Blackman y Eastop, 1994; Voegtlin et al., 2003; Zamora Mejías et al., 2012; Arguedas, 2017). Desde hace aproximadamente diez años, el "trips" Gynaikothrips uzeli (Phlaeothripidae, Thysanoptera) se encuentra afectando el follaje de árboles de sombra de Ficus benjamina, produciendo una agalla simple en las hojas tiernas que las deforma y eventualmente pueden caer, sin embargo, hasta el presente los daños no son severos pero el valor ornamental del hospedero es reducido y los adultos pueden provocar irritaciones en la piel de los visitantes del arbolado (Fig. 3.B) (Held et al., 2005 Rodríguez y Retana, 2010; Arthurs et al., 2016; Mascarenhas et al., 2016). También es común observar daños producidos por ácaros de la familia Tetranychidae, los cuales son "arañitas" diminutas con aparato bucal raspador succionador que se alimentan en el envés de las hojas, en el haz se observa una decoloración clorótica (O’Farril-Nieves y Medina-Gaud 2007, Cibrián 2013). 

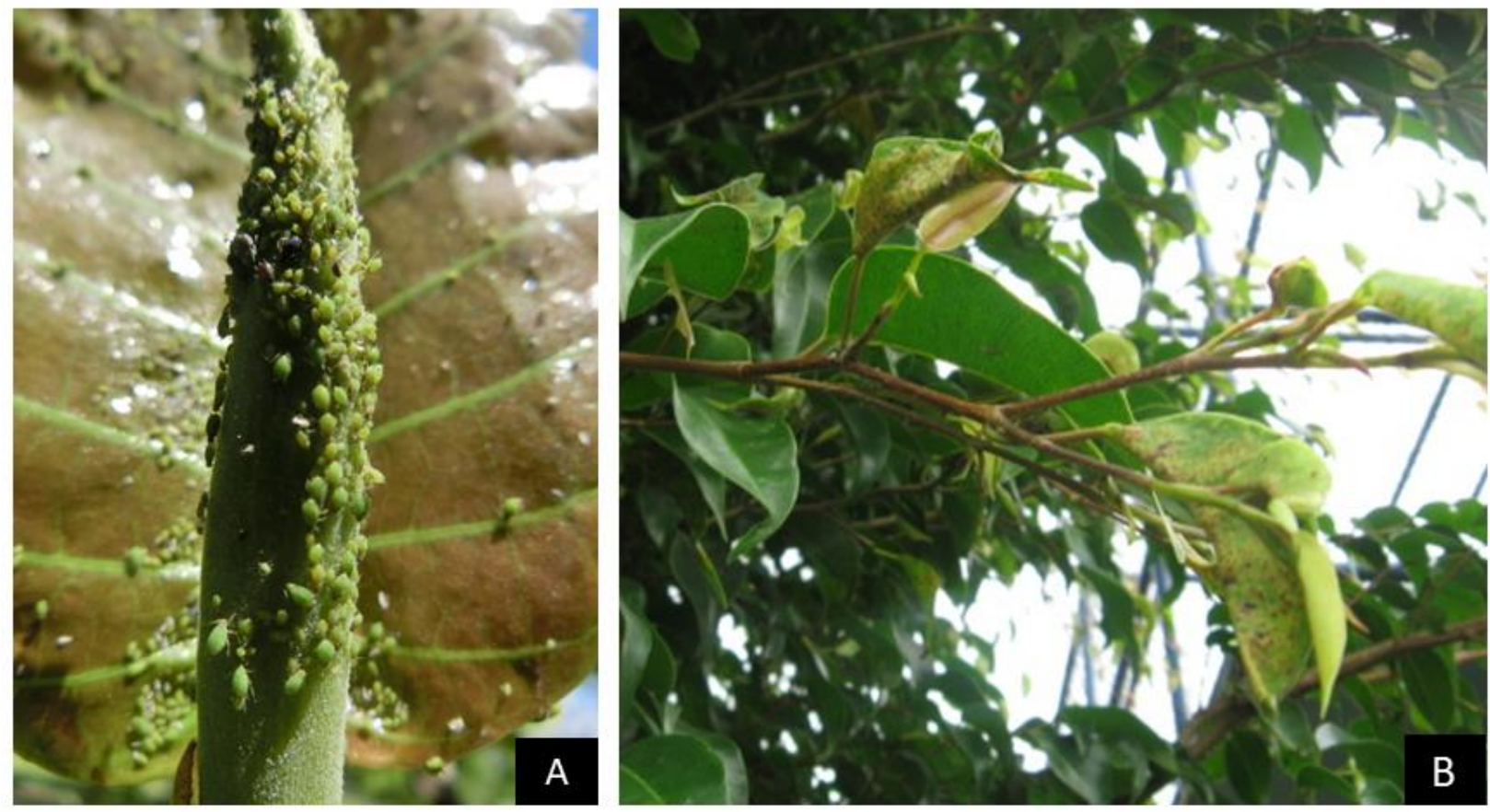

Figura. 3. Daños por insectos succionadores. A, Aphis sp.(Aphididae, Homóptera) en brotes y follaje de Coccoloba caracasana; B, Gynaikothrips sp. (Phlaeothripidae, Thysanoptera) en follaje de Ficus benjamina. San José, Costa Rica.

\section{Barrenadores de fuste y ramas}

La mayor parte de los barrenadores de ramas y fuste son larvas de los órdenes Lepidoptera y Coleoptera, adultos de Coleoptera (Arguedas 2004, Arguedas y Rodríguez 2016) o poblaciones completas de Isoptera (termitas); también hay especialización por los diferentes tejidos que constituyen estas partes de los árboles. Existe un grupo muy importante de insectos denominados "descortezadores", representados por diminutos abejones (Curculionidae, Scolytinae) que se alimentan en el líber, donde producen cadenas enormes de galerías que se unen entre sí y producen anillamiento y muerte de los individuos afectados como Scolytodes alni en Alnus acuminata (Fig. 4.A) (Arguedas y Scorza, 1992; Espinoza y Arguedas 2005). Otros barrenadores de fuste no afectan sensiblemente el desarrollo de los árboles ornamentales, pero pueden permitir la entrada de patógenos y disminuyen su valor estético como Apate monachus (Bostrichidae, Coleoptera) en Casuarina equisetifolia; el adulto es muy delgado y puede medir hasta $20 \mathrm{~mm}$ de largo; en el orificio de entrada de la galería, el árbol produce exudaciones color rosa y malolientes, donde se desarrollan larvas de insectos oportunistas como moscas (Fig. 4.B) (Liu et al., 2008; Wagner et al., 2008; Durai et al., 2017). 

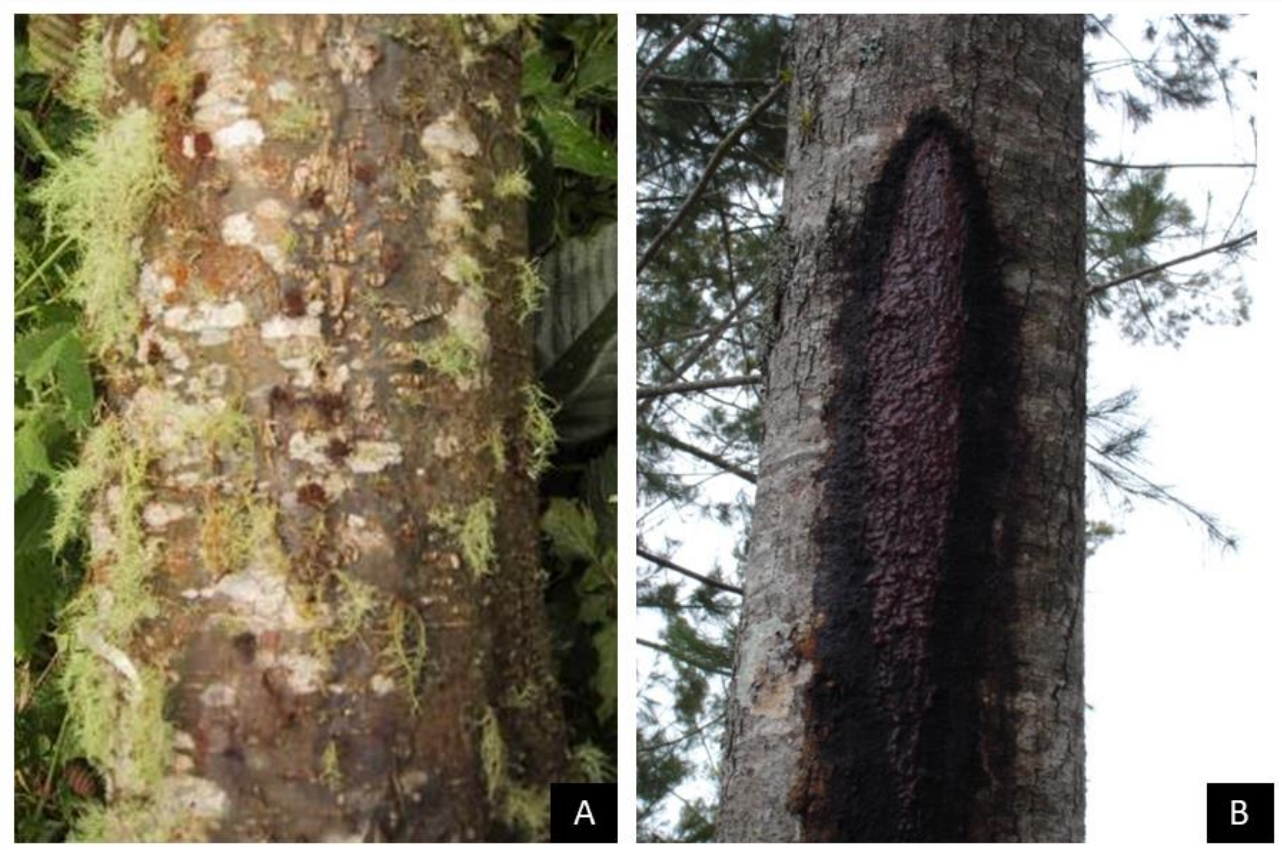

Figura. 4. Daños por coleópteros en el fuste. A, Scolytodes alni (Curculionidae, Scolytinae) en el líber de Alnus acuminata (perforaciones); B, Exudaciones en Casuarina equisetifolia desde perforación causada por Apate monachus (Bostrichidae, Coleoptera). San José, Costa Rica.

\section{ENFERMEDADES INFECCIOSAS}

Las enfermedades causadas por fitopatógenos (organismos capaces de producir infecciones en las plantas) se denominan enfermedades bióticas o infecciosas. Estos patógenos son en su mayoría microorganismos como hongos, bacterias, virus, micoplasmas, protozoos, y algunos organismos mayores como nematodos y plantas parásitas (Arauz, 1998; Agrios, 2005; Sinclair \& Lyon, 2005; Cibrián et al, 2007).

\section{Enfermedades producidas por hongos}

Los hongos son organismos con un núcleo bien definido, sin capacidad de producir sus propios alimentos, se reproducen sexual o asexualmente, y su cuerpo vegetativo está formado por filamentos ramificados que pueden compactarse para formar cuerpos reproductivos o estructuras de sobrevivencia; constituyen el grupo de fitopatógenos más numeroso y son capaces de producir síntomas en todos los cultivos y en todas las partes de las plantas, causando pérdidas económicas considerables (Arauz, 1998; Agrios, 2005).

En el follaje se presenta una gran cantidad de afecciones por hongos, que producen necrosis generalizadas como manchas y tizones que afectan el valor estético de los árboles y su desarrollo. Varias especies de cupresáceas de los géneros Cupressus, Thuya, etc., son severamente afectadas por tizones producidos por Cercospora sp., Pestalotia sp. y Phoma sp., que llegan a producir defoliaciones importantes (Fig. 5.A), específicamente en $C$. lusitanica, se han reportado síntomas que inician en las ramas inferiores y en el follaje más cercano al fuste, las escamas enfermas toman coloraciones anaranjadas o rojizas y sobre ellas se forman pequeños signos de color negro, correspondientes a los cuerpos fructíferos de los hongos (acérvulos producidos por Pestalotia sp. y estromas producidos por Cercospora sp.) (Arguedas, 2007; Arguedas, 2008b).

Especies de Ficus, las cuales son muy utilizadas en arboricultura por la sombra que brindan durante todo el año, presentan manchas extensivas que disminuyen su valor estético, como Phyllachora sp. (Fig. 5.B) (Sáenz y Lizano, 1981) y la mancha "asfalto" producida por Ophiodothella sp. (Fig. 6) (Swart, 1982; Weaver, 2005). 

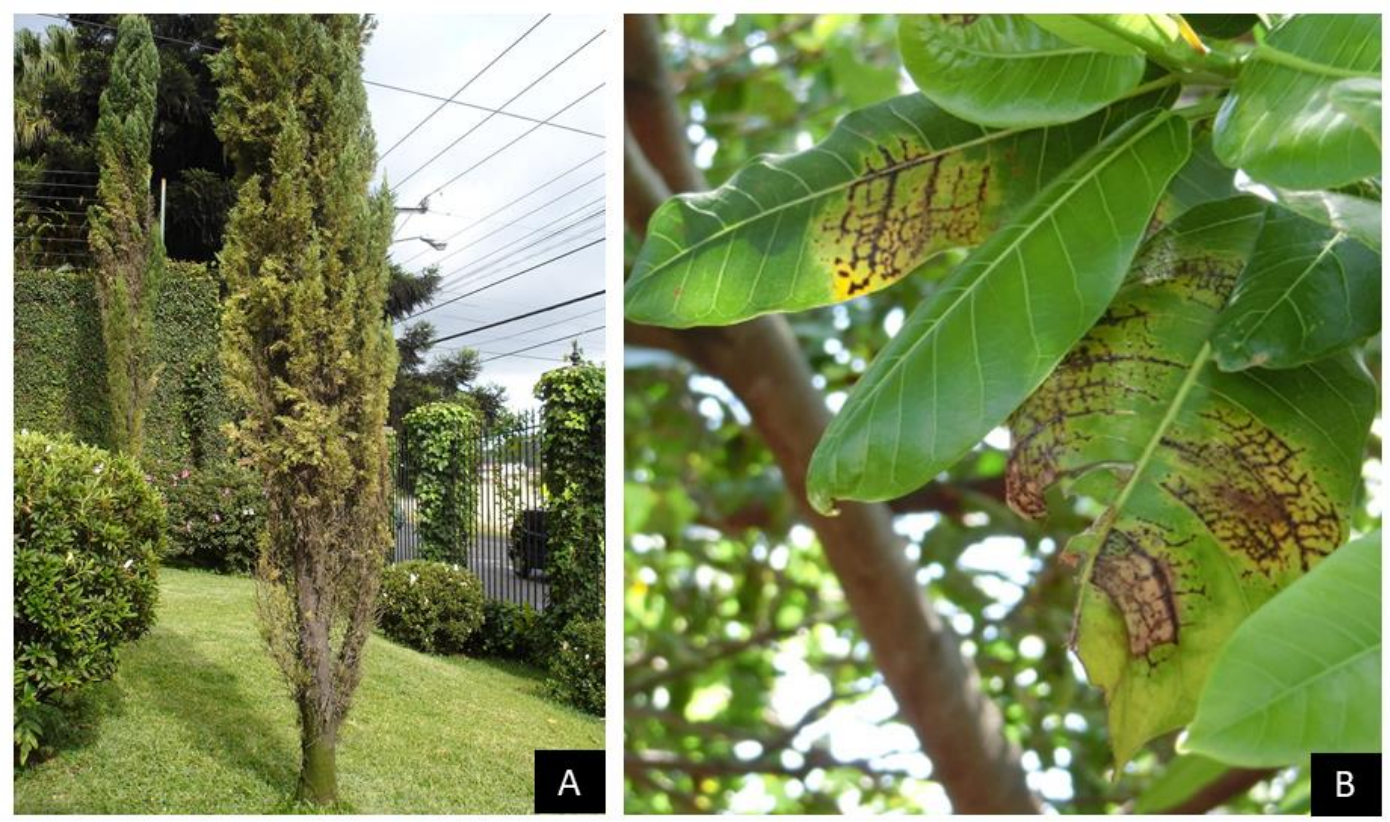

Figura. 5. Daños por hongos en follaje. A, Tizón por Pestalotia sp. en Cupressus columnaris; B, Mancha por Phyllachora stahlii en Ficus goldmani San José, Costa Rica.
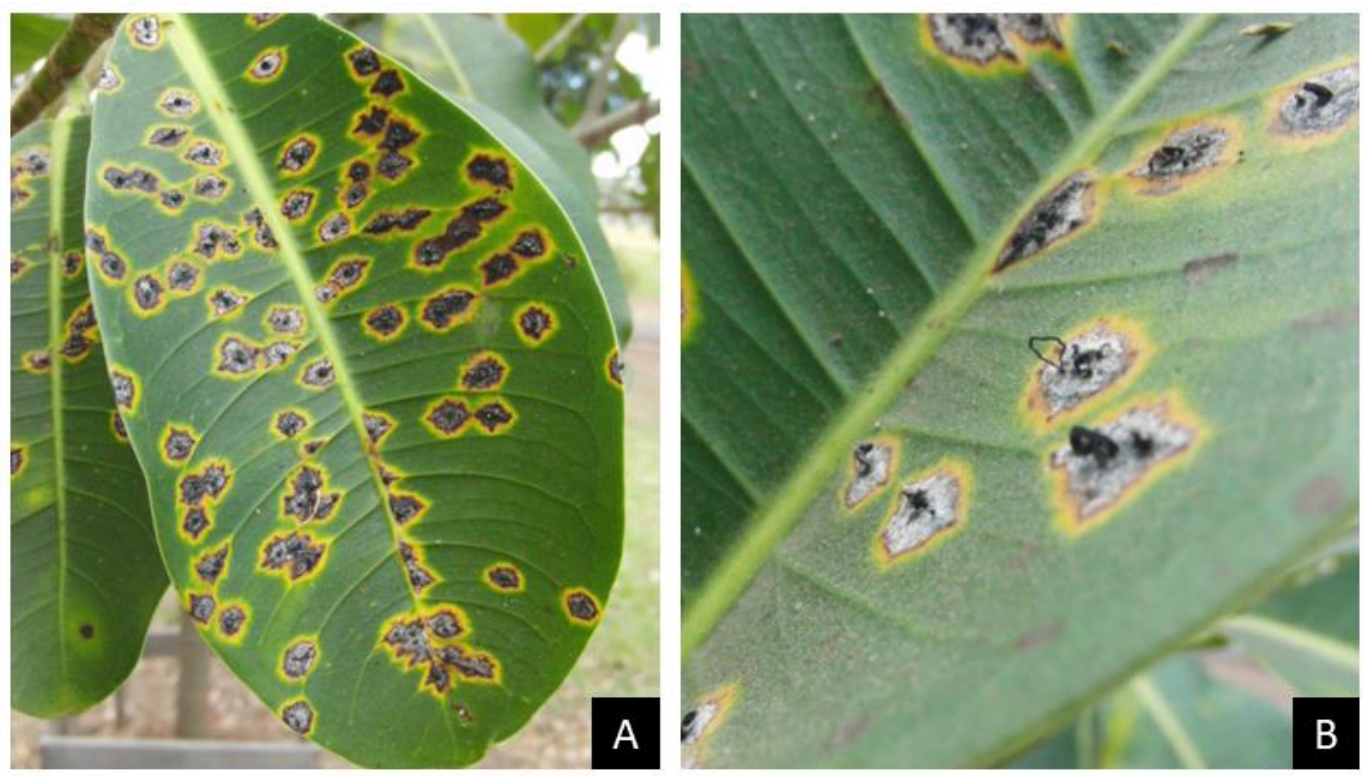

Figura. 6. Mancha "asfalto" (Ophiodothella sp.) en Ficus sp. A. Aspecto general del daño en la lámina foliar; B. Producción de cirrios sobre el área necrosada por las manchas. San José, Costa Rica.

En especies del género Eucalyptus, se han reportado patógenos causantes de manchas y chasparrias, entre ellos: Cylindrocladium sp., Botrytis sp. y Colletotrichum sp. Cylindrocladium sp. es un patógeno capaz de producir afectación tanto en hojas como en brotes, el desarrollo de los síntomas se observa desde la base hacia arriba y desde el centro hacia afuera; en las hojas maduras, el daño es más severo y en casos muy graves, se puede producir defoliación e incluso la muerte del árbol (Rodas et al., 2005). El moho gris producido por Botrytis sp., es uno de los patógenos que causan las enfermedades más comunes y más ampliamente distribuidas por el mundo, produce una esporulación abundante de color gris en los tejidos infectados (Alfenas et al., 2004; Agrios, 2005; Júnior et al., 2013). Igualmente, es posible observar en hojas de Eucalyptus manchas circulares de color marrón a rojizas provocadas por Colletotrichum sp. que pueden causar defoliación (Rodrigues et al. 2014). Además, se reporta en Cedrela odorata y $C$. tonduzzi, la mancha "puntual" de las meliáceas, producida por el 
patógeno Phyllachora balansae, el cual, se ha encontrado haciendo lesiones pequeñas de color amarillo que conforme avanza la infección produce manchas subcirculares, irregulares de color marrón (Fig. 7.A) (Ferreira, 1989; Zacaroni et al., 2013). También se identifica Phyllachora barkeriana en Cassia fistula, Apiosphaeria sp. en Tabebuia ochracea (Fig. 7.B) y Oidium sp. en Euphorbia cotinifolia, Syzygium paniculatum (mirtácea), T. rosea y T. ochracea, entre otras (Arguedas 2017; Guterres et al., 2018; Estay, 2020).
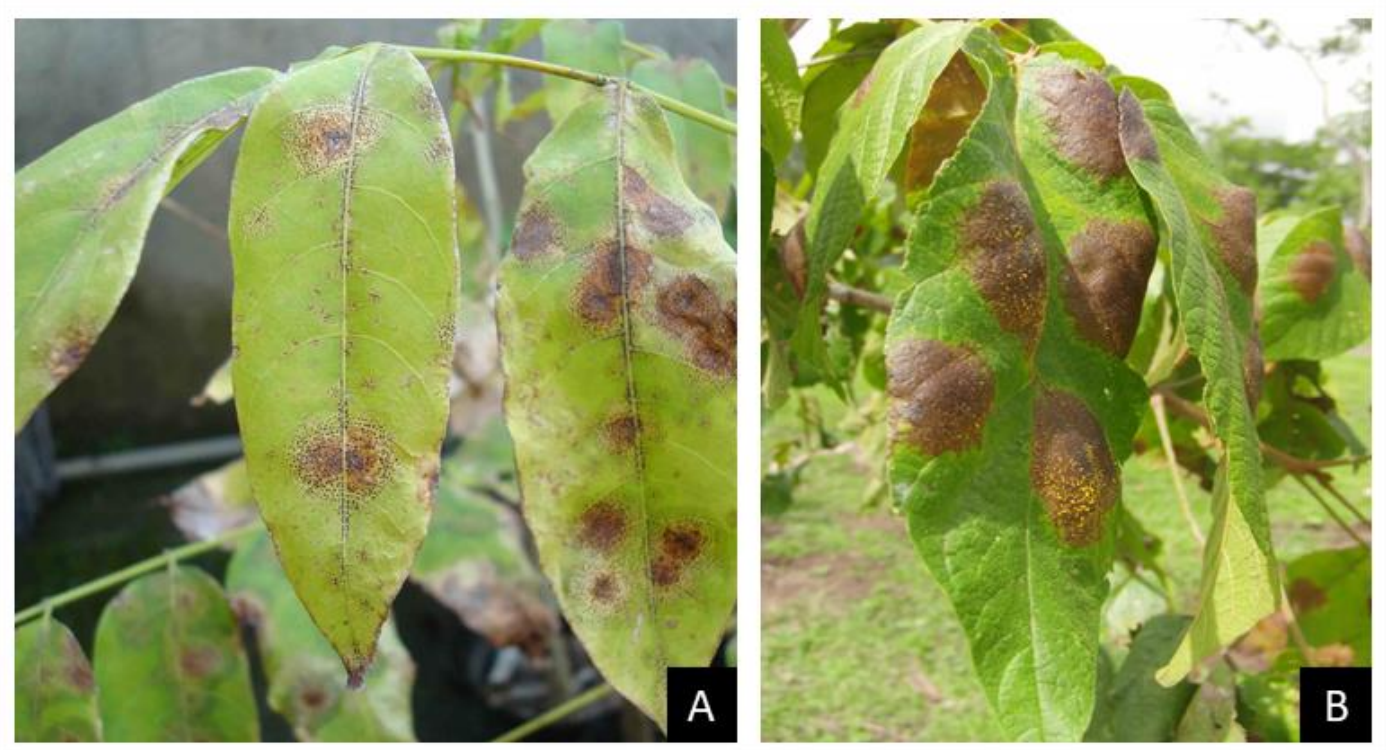

Figura. 7. Daños por hongos en follaje. A, mancha "puntual" por Phyllachora balansae en Cedrela odorata; B, Mancha por Apiosphaeria sp. en Tabebuia ochracea. San José, Costa Rica.

Varios hongos que producen las denominadas "royas", pertenecientes al orden Uredinales, pueden causar serias afecciones al follaje, como Melampsoridium alni en Alnus acuminata, Colesporium plumeriae en Plumeria rubra (Fig. 8.A), Prospodium appendiculatum en Tecoma stand, Puccinia psidii en especies de mirtáceas (Fig. 8.B), Melampsora sp. en especies de Populus, etc. Esta última roya mencionada causa afecciones y defoliaciones continuas en Populus deltoides, lo que ha limitado sustancialmente el uso de esta bella especie en la arboricultura de la ciudad de San José, Costa Rica (Fig. 8.C) (Arguedas, 2007).
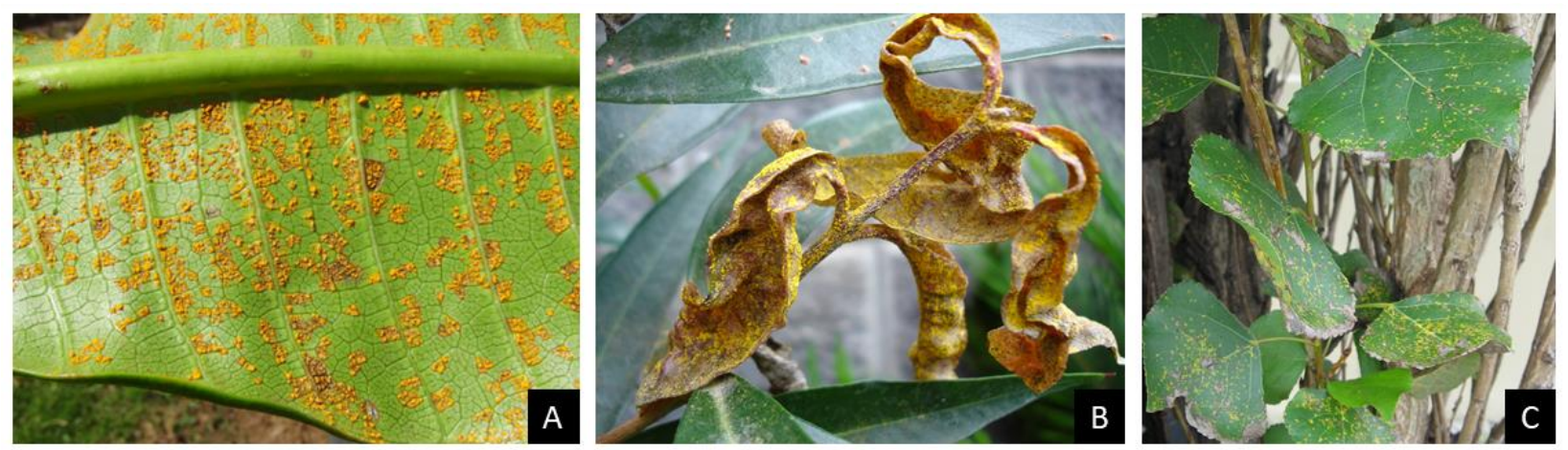

Figura. 8. Royas en follaje. A, Colesporium plumeriae en Plumeria rubra; B, Puccinia psidii en Syzygium jambos; C, Melampsora sp. en Populus deltoides. San José, Costa Rica.

Muchos individuos de arboricultura, sufren daños en las ramas y fuste denominados cancros, los cuales consisten en lesiones necróticas en los tejidos corticales. Los cancros también afectan la belleza del arbolado, pero lo más severo es que puede afectar seriamente su desarrollo y algunos árboles se quiebran en los puntos 
enfermos (Tattar, 1978, Agrios, 2005).

Especies de Eucalyptus son atacadas por el cancro producido por Cryphonectria cubensis, caracterizado por lesiones superficiales en la corteza, generalmente cerca de la base, las cuales pueden profundizarse y extenderse a lo largo del fuste. Los árboles afectados, como mecanismo de defensa, producen callos en los bordes de las necrosis y forman una corteza necrofiláctica, lo que caracteriza un cancro abultado con la corteza exfoliante en tiras longitudinales. Se han presentado casos en que las grandes dimensiones de los cancros pueden llegar a anillar y matar árboles de grandes tamaños (Fig. 9.A) (Arguedas, 1993b; Agrios, 2005; Sinclair y Lyon, 2005). Se reporta también un cancro severo en Melaleuca leucadendron (Fig. 9.B).
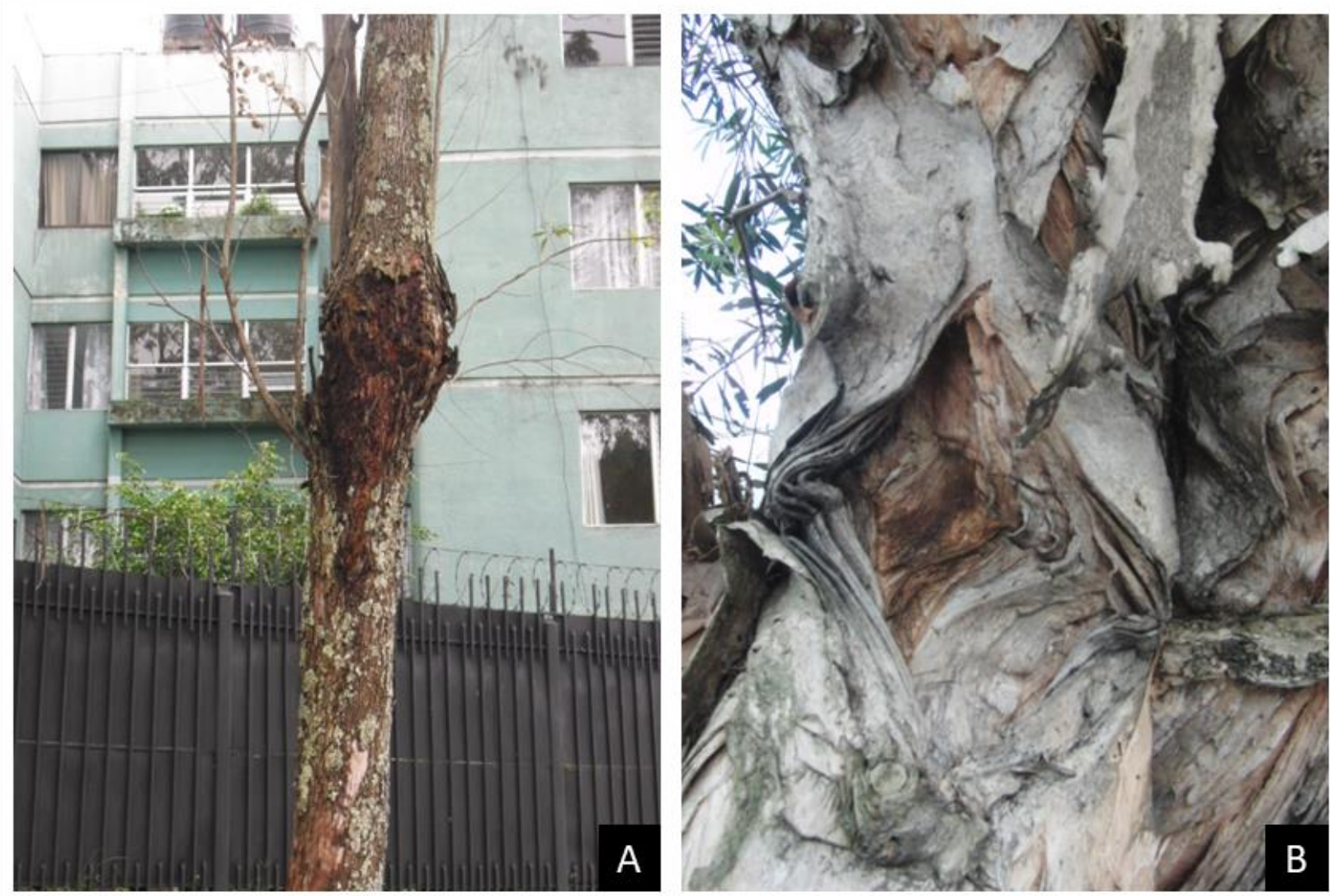

Figura. 9. Cancros en el fuste. A, Cryphonectria cubensis en Eucalyptus grandis; B, Cancro en Melaleuca leucodendron. San José, Costa Rica.

Rodales cultivados y árboles de ornamentación de $C$. lusitanica en Costa Rica, han presentado procesos de mortalidad ocasionados por Seiridium sp. Este patógeno produce cancros en las ramillas, ramas y fuste; muchos de estos cancros pueden también llegar a abarcar el perímetro de la parte afectada, el efecto acumulativo de muchas infecciones en un árbol puede producir mortalidad (Fig. 10). Esta situación ha producido mucha preocupación entre los reforestadores y arboricultores, ya que especies de Seiridium han causado efectos devastadores en especies de Cupresaceae y Taxodiaceae en varias regiones del mundo (Agrios, 2005; Sinclair y Lyon, 2005, Arguedas 2008b).

Durante los últimos diez años aproximadamente, se ha presentado mortalidad de arbolado de Casuarina equisetifolia y de Ficus benjamina por afecciones corticales producidas por Dothiorella casuarini y Phomopsis sp., respectivamente (Lima et al., 2005; De Wet et al., 2009; Pitt et a.l, 2015) 

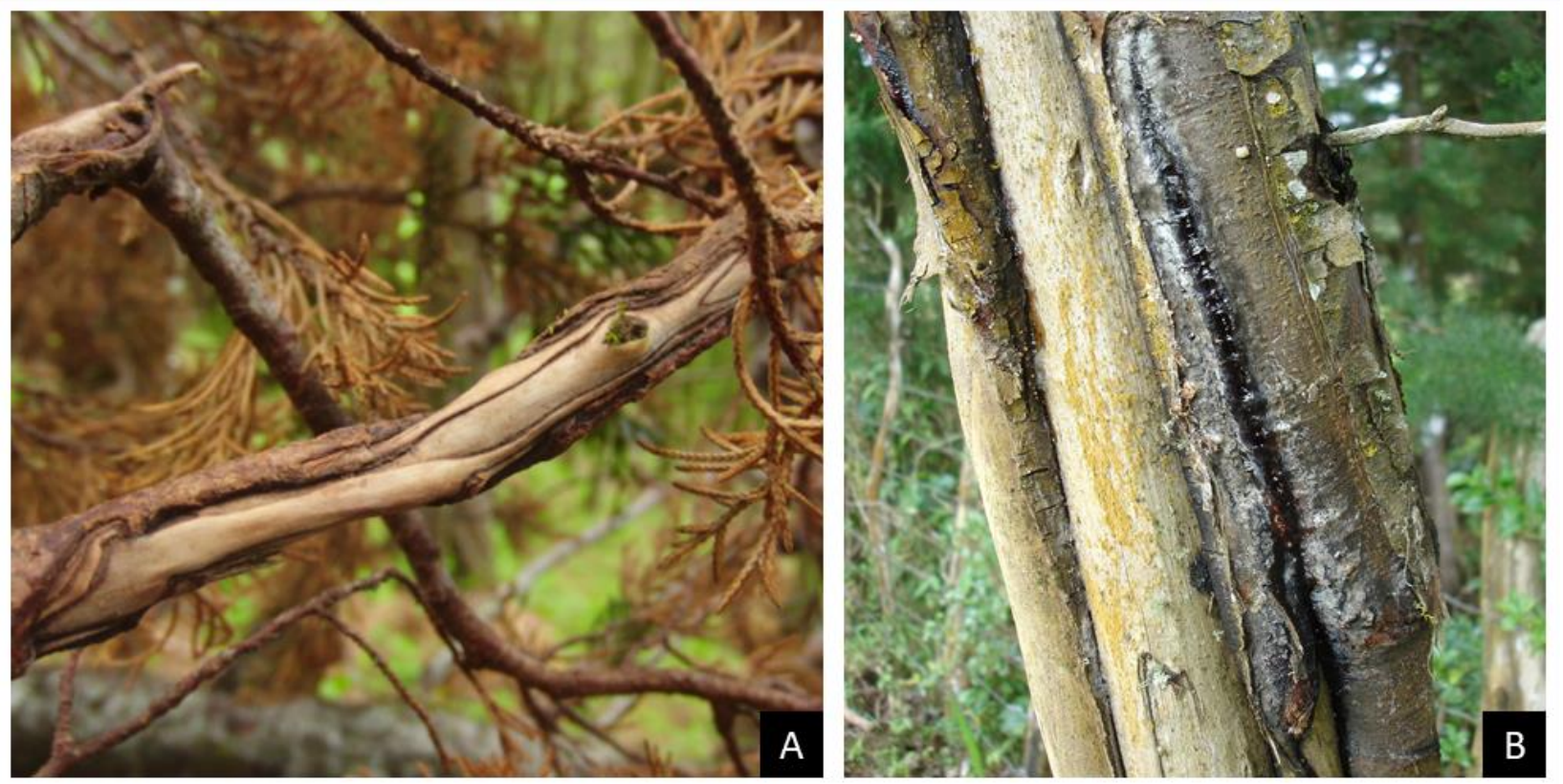

Figura. 10. Cancros producidos por Seiridium sp. en Cupressus lusitanica. A, ramillas; B, fuste. San José, Costa Rica.

\section{Enfermedades producidas por bacterias}

Las bacterias son microorganismos simples, unicelulares, que no poseen membrana nuclear rodeando su material genético. Aquellas bacterias fitopatógenas, pueden ingresar a la planta a través de aberturas naturales como estomas, hidatos o lenticelas, por heridas en hojas, tallos y raíces o ser introducidas por insectos fitófagos. Los síntomas causados por estos patógenos pueden ser muy variados, desde mosaicos, y manchas en las hojas o frutos, tizones o muerte de tejidos en hojas y tallos, pudriciones de raíces, marchitez y agallas (Vidaver, y Lambrecht 2004). La bacteria Agrobacterium tumefaciens produce una enfermedad muy extendida en el mundo denominada la "corona de agallas", se caracteriza por formar agallas o tumores, principalmente en la base de los tallos a nivel de la superficie del suelo. Inicialmente forma pequeños crecimientos esféricos con la apariencia de callos, los cuales crecen rápidamente hasta constituirse en grupos de protuberancias fácilmente distinguibles (Arguedas 2008a). En arboricultura se ha observado en árboles adultos de Taxodium mucronatum y Melaleuca quinquenervia (Fig. 11). 


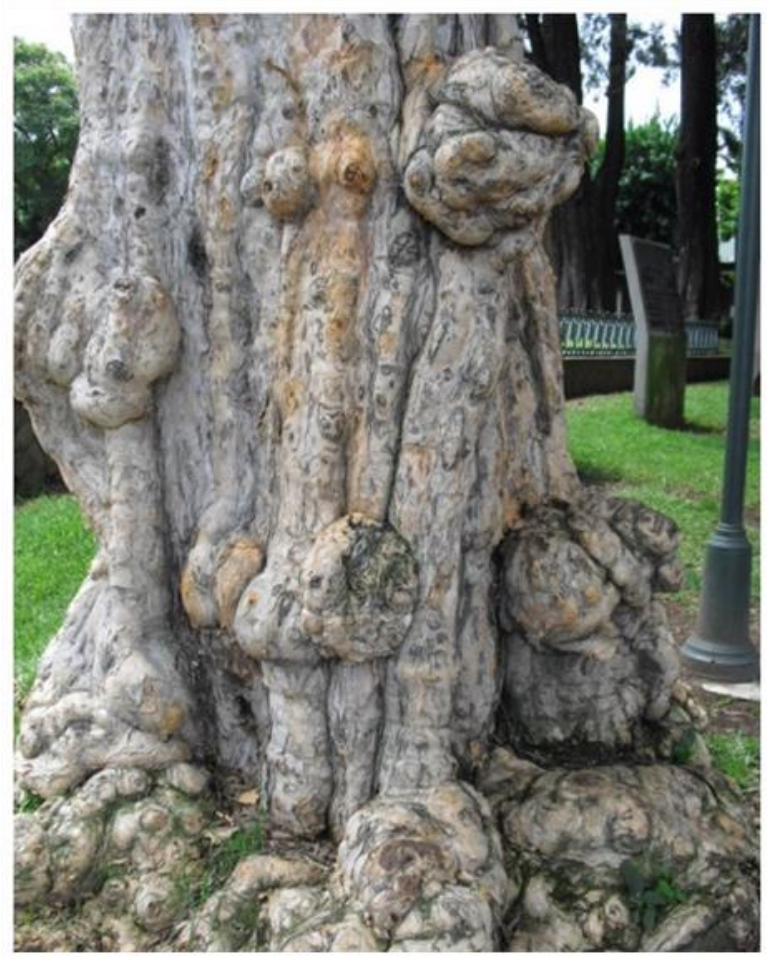

Figura. 11. Protuberancias en el fuste producidas por Agrobacterium tumefaciens en Melaleuca quinquenervia.

\section{Plantas parásitas}

Las plantas hemiparásitas aéreas denominadas "muérdagos", se han proliferado en el arbolado urbano del Gran Área Metropolitana en los últimos años. Las pertenecientes a la familia Loranthaceae, son epífitas escadentes, de hojas simples opuestas, subopuestas, raramente verticiladas o alternas, de lámina entera coreácea o papirácea y los cloroplastos enmascarados por pigmentos amarillentos. Poseen semillas con coberturas viscosas que les permiten adherirse a la rama o fuste del hospedero, poco después comienza la germinación y el extremo radicular del embrión forma una especie de disco de donde se da la penetración y luego se forma un sistema interno de haustorios. Estas plantas, no solo afectan el hospedero al obtener agua y nutrimentos de él, sino que, en algunas ocasiones, sus partes aéreas pueden cubrir una gran parte del follaje, interfiriendo en procesos como la fotosíntesis. Muchos muérdagos están asociados a pájaros para la polinización y la diseminación de semillas, en este último proceso también se reportan otros vertebrados. Las especies observadas, pertenecen principalmente a los géneros Phoradendron, Psittacanthus y Struthanthus (Fig. 12) (Restrepo et al., 2002; Lobo, 2003; Vidal-Russell \& Nickrent, 2008; Cibrián 2013). 

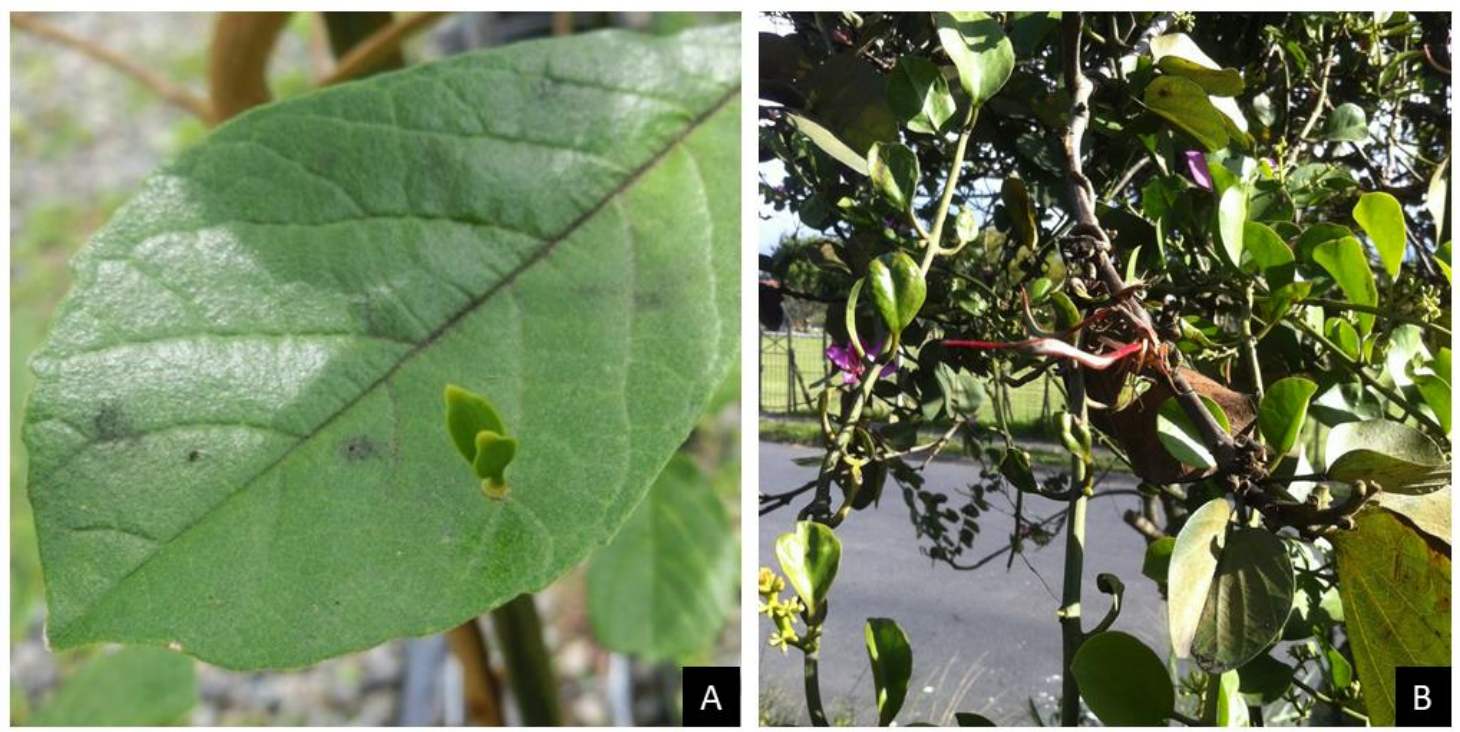

Figura. 12. Muérdagos. A. Plántula recién germinada de semilla adherida a foliolo de Tabebuia rosea; B. Struthanthus orbicularis en Bauhinia purpurea.

\section{DAÑOS POR AGENTES ABIÓTICOS}

Las afecciones de los árboles producidas por agentes abióticos también son conocidas como enfermedades no infecciosas. Representan uno de los mayores obstáculos para el desarrollo adecuado de los árboles de ciudad. Además de condiciones climáticas extremas como las sequías, las inundaciones, la exposición solar, los vientos y los rayos, puede considerarse que la contaminación ambiental y las limitaciones de los sustratos, son las más importantes para este tipo de arbolado (Fig. 13).

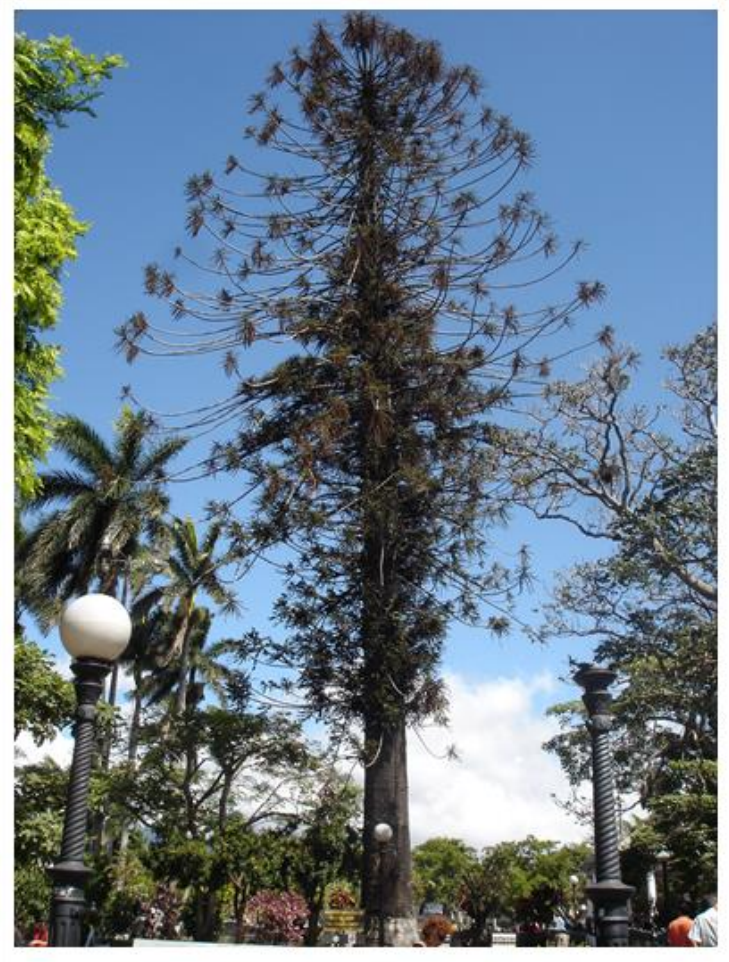

Figura. 13. Araucaria emblemática del Parque central de Heredia (Costa Rica), afectada por un rayo. 
El efecto de la contaminación ambiental, y especialmente la contaminación atmosférica, en las plantas ha cobrado mucho interés en las últimas décadas, principalmente por el efecto que ha tenido en la destrucción de grandes extensiones de bosque en países industrializados de Europa y Norteamérica. En países de menos desarrollo industrial el daño por contaminación ambiental es más notorio en la cercanía de las fábricas o de las carreteras muy transitadas. Entre los contaminantes del ambiente que causan daños a las plantas están el ácido fluorhídrico (HF), el dióxido de azufre (SO2), el etileno, los óxidos de nitrógteno (NOx), el Ozono (3) y el nitrato de peroxiacetileno (PAN) (Arauz 1998; Sinclair y Lyon, 2005; Tattar, 1978).

La contaminación atmosférica, puede causar efectos directos sobre las plantas urbanas que incluye cambios morfológicos, estructurales y bioquímicos como caída de hojas y estructuras reproductivas, pérdida de pigmentos fotosintéticos (clorosis blanquecina o generalizada), reducción del área foliar, disminución de la síntesis de proteínas y carotenoides, aumento en la concentración de metales pesados y cambios en los estomas (Pardos 2008; Gostin, 2009; Pourkhabbaz et al., 2010; Ferriol et al., 2014); y efectos indirectos, como la acidificación del suelo con la liberación de aluminio y otros metales pesados (Pardos, 2008). En la Fig. 14 se logran observar diferentes síntomas y efectos producidos por contaminantes ambientales en San José, Costa Rica.
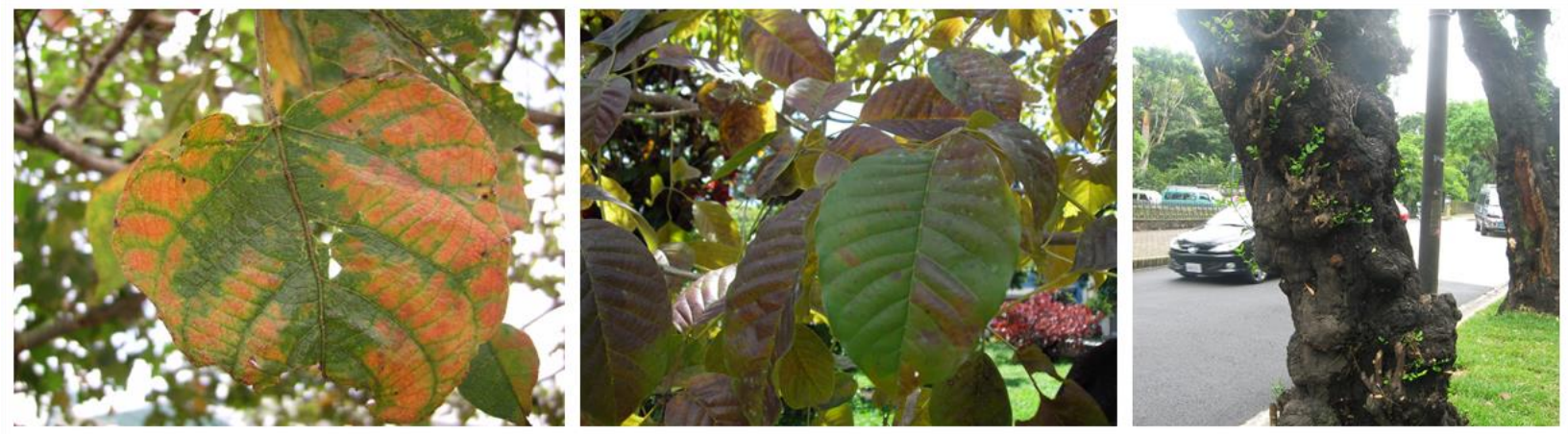

Figura. 14. Diferentes síntomas y efectos producidos por contaminantes ambientales en San José, Costa Rica. (Primera fotografía cortesía de J. Hernández).

La disponibilidad en calidad y cantidad de los suelos donde se desarrollan generalmente los árboles en las ciudades es uno de los factores críticos para el desarrollo normal de las raíces de los árboles y por tanto de todo el individuo (Manion 1981, Alvarado et al 2014). El sistema radicular de la mayoría de los árboles está compuesto por raíces laterales ubicadas entre los primeros 50 y 100 centímetros de profundidad y se pueden extender hacia los lados, tres veces o más el área de la copa; por tal motivo, en el arbolado urbano, el espacio lateral libre de elementos extraños, de suelos compactados o alterados debe ser como mínimo igual al tamaño de la copa (Fernández y Vargas, 2011, Boa 2008). Generalmente el volumen efectivo para el desarrollo radicular es menor que el requerido y otros factores muy comunes de las zonas urbanizadas, como capas de suelo endurecidas a diferentes profundidades; capas de cemento, asfalto o totalmente compactadas en la superficie y suelos extremadamente limosos o arenosos, además de afectar en forma directa a las raíces, alteran las condiciones ideales de aireación y de regímenes hídricos fundamentales para el sistema radical (Fig. 15). 

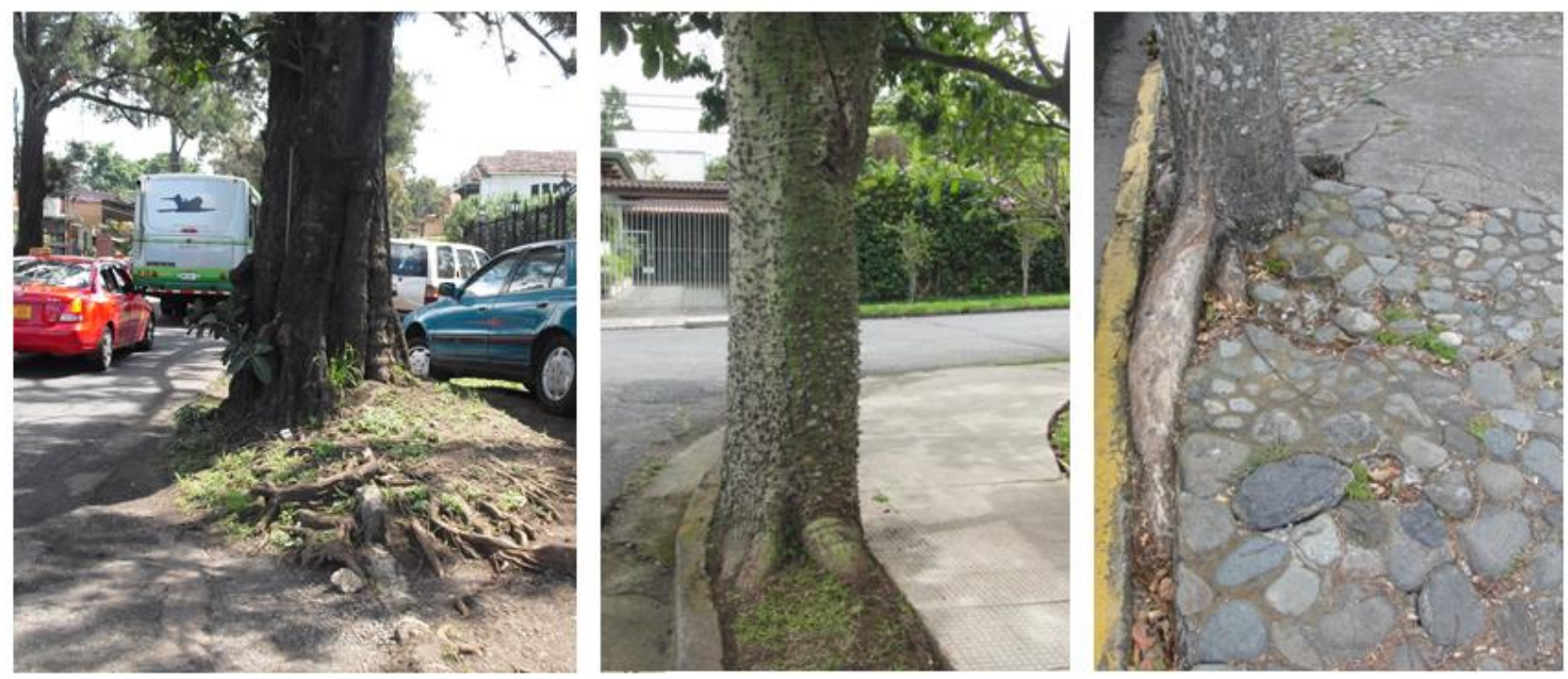

Figura. 15. Árboles con sistemas radiculares afectados por suelos extremadamente compactados y capas de cement/o y asfalto. San José, Costa Rica.

\section{CONSIDERACIONES FINALES}

La sanidad forestal en arbolados urbanos presenta características particulares, que difieren de los postulados aplicados para la sanidad en otros ecosistemas como las plantaciones forestales. La principal diferencia es que la mayor parte de los casos, en arboricultura, cada individuo cumple una función particular en el paisaje y merece la protección absoluta.

Estos arbolados se encuentran en sitios de mucha visitación por la población, por lo que su condición sanitaria debe ser tan buena, que garantice la seguridad de todos los visitantes.

Los problemas fitosanitarios que presentan los arbolados urbanos están más relacionados con condiciones limitantes de desarrollo, que con agentes bióticos propiamente. Muchas veces, los agentes causales de plagas y enfermedades presentes son oportunistas.

El manejo de problemas fitosanitarios en este tipo de vegetación debe ser analizado para cada caso en particular, tomando en cuenta la especie afectada, el agente causal, el tipo y la severidad del daño, el objetivo del arbolado y las condiciones del entorno.

\section{Referencias}

ABM (Alcaldía Mayor de Bogotá D.C.). (2009). Manual de Silvicultura Urbana para Bogotá. Bogotá, CO. Agrios, G.N. (2005). Plant Pathology. Fifth Edition.. London, UK: Elvesier Academic Press.

Alfenas, A. C., Zauza, E. A. V., Mafia, R. G., \& De Assis, T. F. (2004). Clonagem e doenças do eucalipto.

Alvarado-Ojea, A., Guajardo-Becchi, F. G. \& Devia-Cartes, S. (2014). Manual de plantación de árboles en áreas urbanas. Santiago, Chile: CONAF.

Arauz, L.F. (1998). Fitopatología: un enfoque agroecológico. San José, CR, Editorial Universidad de Costa Rica.

Arguedas, M. \& Scorza, F. (1992). Observaciones sobre la biología de Scolytodes alni (Coleoptera: Scolytidae) descortezador del jaúl Alnus acuminata. Manejo Integrado de Plagas (CR), 20-21, 23-25.

Arguedas, M. (1993a). Protejamos los árboles ornamentales. Biocenosis, 8 (1-2), 19-20.

Arguedas, M. (1993b). El cancro del eucalipto, Chrysoporthe cubensis. (Serie Plagas y EnfermedadesForestales $\mathrm{N}^{\mathrm{o}}$ 8). Cartago, CR, ITCR-CIT.

Arguedas, M. (2004). Escarabajos barrenadores de la madera: reconocimiento de daños y manejo. Kurú: Revista Forestal (Costa Rica), 1(1), 92-94

Arguedas, M. (2006a). Clasificación de tipos de daños producidos por insectos forestales. Segunda parte. Kuru: $\begin{array}{lllllll}\text { Revista Forestal (Costa Rica), } & 3(9), & \text { p. } & \text { Recuperado de }\end{array}$ 
http://tecdigital.tec.ac.cr/servicios/ojs/index.php/kuru/article/view/508

Arguedas, M. (2006b). Clasificación de tipos de daños producidos por insectos forestales. Segunda parte. Kuru: Revista Forestal (Costa Rica), 3(8), 6 p. Recuperado de http://tecdigital.tec.ac.cr/servicios/ojs/index.php/kuru/article/view/518

Arguedas, M. (2007). Plagas y enfermedades forestales en Costa Rica. Kurú: Revista Forestal (Costa Rica), $\begin{array}{lllllll}4(11 & \text { y } & 12 & \text { especial }), & 69 & \text { p. } & \text { Recuperado de }\end{array}$ http://tecdigital.tec.ac.cr/servicios/ojs/index.php/kuru/article/view/494

Arguedas, M. (2008a). Diagnóstico de plagas y enfermedades forestales en Costa Rica. Ciencia e Investigación Forestal $(\mathrm{CH}), 1(14), 167-179$.

Arguedas, M. (2008b). Problemas fitosanitarios del ciprés (Cupressus lusitanica Mill) en Costa Rica. Kurú: Revista Forestal (Costa Rica), 5(13), 8 p. Recuperado de http://tecdigital.tec.ac.cr/servicios/ojs/index.php/kuru/article/view/469

Arguedas, M. (2017). Plagas y enfermedades forestales en Costa Rica / Forest pest and diseases in Costa Rica. Cartago, Costa Rica: Editorial Tecnológica.

Arguedas, M. \& Rodríguez, M. (2016). Insectos barrenadores del xilema en especies forestales comerciales en Costa Rica/Xylem insect borers in commercial forest species in Costa Rica. Revista Mexicana en Ciencias Forestales, 7(35), 79-89.

Arthurs, S. P., Chen, G., \& Chen, J. (2016). Host specificity evaluation for Gynaikothrips uzeli (Thysanoptera: Phlaeothripidae) on ornamental Ficus (Rosales: Moraceae). Florida Entomologist, 481-486.

Blackman, R. L., \& Eastop, V. F. (1994). Aphids on the world's trees: an identification and information guide. Wallingford, Oxon: Cab International.

Boa, E. (2008). Guía ilustrada sobre el estado de salud de los árboles Reconocimiento e interpretación de síntomas y daños. San Salvado, El Salvador: FAO-OIRSA.

CATIE (Centro Agronómico Tropical de Investigación y Enseñanza, CR). (1991). Plagas y enfermedades forestales en América Central. Guía de campo. Turrialba, CR, CATIE.

Cibrián, D., Alvarado, D. \& García, S. (2007). Enfermedades Forestales en México. Chapingo, MX, Universidad Autónoma de Chapingo.

Cibrián, D. (2013). Manual para la identificación y manejo de plagas en plantaciones forestales comerciales. Texoco, México: Un. Autónoma de Chapingo.

Cibrián, D. (2017). Fundamentos de Entomología Forestal. Chapingo, MX, Universidad Autónoma de Chapingo.

De Wet, J., Slippers, B., Preisig, O., Wingfield, B. D., Tsopelas, P., \& Wingfield, M. J. (2009). Molecular and morphological characterization of Dothiorella casuarini sp. nov. and other Botryosphaeriaceae with diplodia-like conidia. Mycologia, 101(4), 503-511.

Durai, M. V., Balu, A., Rishi, R. R., \& Karthikeyan, A. (2017). First Report of Apate monachus (Coleoptera: Bostrychidae) in big-leaf mahogany (Swietenia macrophylla King) plantations in India. Journal of Entomology and Zoology Studies, 5(6), 1900-1902.

Escobedo, F. J., Kroeger, T., \& Wagner, J. E. (2011). Urban forests and pollution mitigation: Analyzing ecosystem services and disservices. Environmental pollution, 159(8-9), 2078-2087.

Espinoza, D. \& Arguedas, M. (2005). Evaluación de factores que favorecen el ataque Scolytodes alni (Curculionidae, Scolytinae) en plantaciones de jaúl (Alnus acuminata Kunth) en Costa Rica. Kuru: Revista Forestal (Costa Rica), 1(5), 11 p. Recuperado de http://tecdigital.tec.ac.cr/servicios/ojs/index.php/kuru/article/view/544

Estay, S. A. (Ed.). (2020). Forest Pest and Disease Management in Latin America: Modern Perspectives in Natural Forests and Exotic Plantations. Springer Nature.

Fernández, P. y Vargas, A. (2011). La ciudad y los árboles: Conflicto entre arbolado e infraestructura. Revista Agronomía y Forestal, 21, 32-36.

Ferreira, F. A. (1989). Patologia Florestal, principais doenças florestais no Brasil. Viçosa, Brazil: Sociedade de Investigações Florestais, $570 \mathrm{p}$.

Ferriol, M., Muñoz, S., Merle, H., Garmendia, A., \& López, C. (2014). Papel de los árboles ornamentales como bioindicadores de la contaminación atmosférica urbana. VI Jornadas Ibéricas de Horticultura Ornamental, Valencia: Las Buenas Prácticas en la Horticultura Ornamental, 1-3.

Gostin, I. N. (2009). Air pollution effects on the leaf structure of some Fabaceae species. Notulae Botanicae Horti Agrobotanici Cluj-Napoca, 37(2), 57-63.

Guterres, D. C., Galvão-Elias, S., de Souza, B. C. P., Pinho, D. B., dos Santos, M. D. D. M., Miller, R. N. G., \& Dianese, J. C. (2018). Taxonomy, phylogeny, and divergence time estimation for Apiosphaeria 
guaranitica, a Neotropical parasite on bignoniaceous hosts. Mycologia, 110(3), 526-545.

Held, D.W, Boyd, D, Lockley, T. \& Edwards G.B. (2005). Gynaikothrips uzeli (Thysanoptera: Phlaeothripidae) in the southeastern United States: distribution and review of biology. Florida Entomologist, 88, 538540.

Jiménez, Q. (2013). Arbolado urbano: beneficios, desaciertos y realidad en la Gran Área Metropolitana. Ambientico, 4(12), 232-233.

Júnior, J. A. S., Auer, C. G., Pimentel, I. C., dos Santos, Á. F., \& Schultz, B. (2013). Seleção in vitro de fungos endofíticos para o controle biológico de Botrytis cinerea em Eucalyptus benthamii. Floresta, 43(1), 145-152.

Laffont, E. R., Godoy, M. C., Galdeano, E., Coronel, J. M., \& Etcheverry, C. (2015). Arbolado de espacios verdes de la Ciudad de Corrientes: Relevamiento de plagas y enfermedades, asesoramiento y capacitación. Extensionismo, Innovación y Transferencia Tecnológica, 2, 129-137.

Lima, M. L. P., Uesugi, C. H., \& Santos, G. R. (2005). Morte progressiva de ramos de Ficus benjamina Causada por Phomopsis cinerescens nos estados de Tocantins e Minas Gerais. Fitopatologia Brasileira, 30(1), 91-91.

Liu, L., Schönitzer, K., \& Yang, J. (2008). A review of the literature on the life history of Bostrichidae. Mitt. Munch. Ent. Ges, 98, 91-97.

Livesley, S. J., McPherson, E. G., \& Calfapietra, C. (2016). The urban forest and ecosystem services: impacts on urban water, heat, and pollution cycles at the tree, street, and city scale. Journal of environmental quality, 45(1), 119-124.

Lobo, S. (2003). Los hospederos de las plantas hemiparásitas de la familia Loranthaceae (SL) en Costa Rica. Lankesteriana 6, 17-20.

Mascarenhas, A. L. S., Junior, S., \& Juvenal, C. (2016). Natural history of Gynaikothrips uzeli (Thysanoptera, Phlaeothripidae) in galls of Ficus benjamina (Rosales, Moraceae). Iheringia. Série Zoologia, 106.

Manion, P.D. (1981). Tree disease concept. New York, US, Prentice-Hall Hinc. 399 p.

Mexzón, R. G., Chinchilla, C., \& Rodríguez, R. (2003). El gusano canasta Oiketicus kirbyi Lands Guilding (Lepidoptera: Psychidae) plaga de la palma aceitera. ASD Oil Palm Papers, (25), 17-28.

Miller, R. W., Hauer, R. J., \& Werner, L. P. (2015). Urban forestry: planning and managing urban greenspaces. Waveland press.

Montoya-Lerma, J., Giraldo-Echeverri, C., Armbrecht, I., Farji-Brener, A., \& Calle, Z. (2012). Leaf-cutting ants revisited: Towards rational management and control. International Journal of Pest Management, 58(3), 225-247. DOI: 10.1080/09670874.2012.663946

O’Farril-Nieves, H., \& Medina-Gaud, S. (2007). Las plagas comunes de los árboles urbanos de Puerto Rico. Identificación y manejo. Mayagüez, Puerto Rico: International Institute of Tropical ForestryUniversidad de Puerto Rico.

Ordóñez, C., \& Duinker, P. N. (2013). An analysis of urban forest management plans in Canada: Implications for urban forest management. Landscape and Urban Planning, 116, 36-47.

Pardos, J. A. (2008). La contaminación atmosférica y los ecosistemas forestales. Forest Systems, 15(4), 55-70.

Pitkin, L. M. (2002). Neotropical ennomine moths: a review of the genera (Lepidoptera: Geometridae). Zoological journal of the Linnean Society, 135(2-3), 121-401.

Pitt, W. M., Úrbez-Torres, J. R., \& Trouillas, F. P. (2015). Dothiorella and Spencermartinsia, new species and records from grapevines in Australia. Australasian Plant Pathology, 44(1), 43-56.

Pourkhabbaz, A., Rastin, N., Olbrich, A., Langenfeld-Heyser, R., \& Polle, A. (2010). Influence of environmental pollution on leaf properties of urban plane trees, Platanus orientalis L. Bulletin of environmental contamination and toxicology, 85(3), 251-255.

Rhainds, M., \& Cabrera-La Rosa, J. C. (2010). Oiketicus kirbyi (Lepidoptera, Psychidae), a key pest in Peruvian orchards of avocado. International journal of pest management, 56(2), 103-107. DOI: 10.1080/09670870903180145

Restrepo, C., Sargent, S., Levey, D. J., \& Watson, D. M. (2002). The role of vertebrates in the diversification of New World mistletoes. Seed dispersal and frugivory: ecology, evolution and conservation, 83-98.

Reyes de la Barra, J., Ponce-Donoso, M., Vallejo-Barra, O., Daniluk-Mosquera, G. y Coelho-Duarte, A.P. (2018). Comparación de cuatro métodos de evaluación visual del riesgo de árboles urbanos. Colombia Forestal, 21(2), 161-173.

Rodas, C. A., Lombard, L., Gryzenhoinf, M., Slippers, B., \& Wingfield, M. J. (2005). Cylindrocladium blight of. Eucalyptus grandis in Colombia. Australasian Plant Pathology, 34(2), 143-149.

Rodrigues, A. L., Pinho, D. B., Lisboa, D. O., Nascimento, R. J., Pereira, O. L., Alfenas, A. C., \& Furtado, G. 
Q. (2014). Colletotrichum theobromicola causes defoliation, stem girdling and death of mini-cuttings of eucalyptus in Brazil. Tropical Plant Pathology, 39(4), 326-330.

Rodríguez-Arrieta, J. A., \& Retana-Salazar, A. P. (2010). Ultra-structure variability of Gynaikothrips uzelificorum (Thysanoptera: Phlaeothripidae) complex in Ficus benjamina from Mexico and Costa Rica. Brenesia, 73, 89-97.

Sáenz, J. A., \& Lizano, A. V. M. (1981). Phyllachora stahlii (Chardon) Stevenson, parásito de Ficus goldmanii: nuevo registro para Costa Rica. Revista de Biología Tropical, 29(2), 295-298.

Salbitano, F., Borelli, S., Conigliaro, M., \& Chen, Y. (2016). Guidelines on urban and peri-urban forestry. Rome, Italy: FAO.

Sinclair, W.A. \& Lyon, H.H. (2005). Disease of trees and shrubs. Second Edition.. New York, US, Cornell University Press.

Sosa-López, A., Molina-Peligrin, Y., Puig-Pérez, A y Riquenes-Valdés, E. (2011). Diagnóstico de la situación del arbolado urbano en la ciudad de guisa. Revista Forestal Baracoa, 30(1), 73-78.

Swart, H. J. (1982). Australian leaf-inhabiting fungi XV. Ophiodothella longispora sp. nov. Transactions of the British Mycological Society, 79, 566-568.

Tattar, T.A. (1978). Diseases of shade trees. New York, US, Academic press.

Wagner, M.R., Cobbinah, J.R. \& Bosu, P.P. (2008). Forest entomology in West Tropical Africa: forest insects of Ghana. 2a ed. London, UK, Springer.

Tovar, G. (2006). Manejo del arbolado urbano en Bogotá. Colombia Forestal. 9(19), 187-205.

Tovar, G. (2013). Aproximación a la arboricultura urbana en Colombia. Bitácora Urbano Territorial, 22(1), 119-136.

Varón, E. H., Eigenbrode, S. D., Bosque-Perez, N.A., \& Hilje, L. (2007). Effect of farm diversity on harvesting of coffee leaves by the leaf-cutting ant Atta cephalotes. Agricultural and Forest Entomology, 9(1), 4755 .

Vidaver, A.K. and P.A. Lambrecht (2004). Las Bacterias como Patógenos Vegetales. Trans. Ana María Romero. The Plant Health Instructor. DOI: 10.1094/PHI-I-2006-0601-01

Vidal-Russell, R., \& Nickrent, D. L. (2008). Evolutionary relationships in the showy mistletoe family (Loranthaceae). American Journal of Botany, 95(8), 1015-1029.

Villalobos, K., Suárez, E., Gaspar, G y Manta, M. (2014). Evaluación fitosanitaria de árboles ornamentales en la Av. Monte de los Olivos, distrito de Surco, Lima. Revista Xilema, 27(1), 33-42.

Voegtlin, D., Villalobos, W., Sánchez, M. V., Saborío-R, G., \& Rivera, C. (2003). Guía de los áfidos alados (Homoptera) de Costa Rica. Revista de Biología Tropical, 1-214.

Wagner, M. R., Cobbinah, J. R., \& Bosu, P. P. (2008). Forest entomology in West Tropical Africa: forest insects of Ghana. Berlin, Alemania: Springer Science \& Business Media.

Weaver, R. E. (2005). Botany section. In: P. J. Anderson \& N. D. Wayne (eds.). Tri-Ology, 44(2), 1-14.

Zacaroni, A. B., Pozza, E. A., Mansur, T. D. O. F., \& Sussel, A. A. B. (2013). Occurrence of Phyllachora balansae in Toona ciliata in Southern Minas Gerais State, Brazil. Summa Phytopathologica, 39(3), 219-220.

Zamora Mejías, D., Pérez Hidalgo, N., Villalobos Muller, W., \& Hanson Snortun, P. (2012). New data about the Costa Rican aphid fauna (Hemiptera, Aphididae). Graellsia, 68(2), 305-312.

Zúñiga-Sánchez, B. (2017). Valoración de la arboricultura y lineamientos para el manejo en 12 parques del cantón de Desamparados, San José, Costa Rica. (Tesis de grado, Instituto Tecnológico de Costa Rica). 